\title{
The Prevalence of Playing-related Musculoskeletal Disorders of Traditional Korean Musical Instrument Player
}

\author{
Jung Yong Kim, Seung Nam Min, Young Jin Cho, Jun Hyeok Choi \\ Department of Industrial and Management Engineering, Hanyang University, Ansan, 426-791
}

\begin{abstract}
Objective: This study was performed to investigate the prevalence of musculoskeletal disorders of traditional Korean instrument player using a variety of traditional classical instruments: Gayageum, Geomungo, Ajaeng, Haegeum, Daegeum, Piri and Samul instruments. Background: A large percentage of instrument players have suffered from the musculoskeletal pain of each body parts. However, there is no research on the prevalence of musculoskeletal disorders of traditional Korean musical instrument players. Method: Through the focus group interview, a questionnaire to investigate musculoskeletal disorders was developed. The questionnaire consisted of four parts: demographic factors, performance factors, musculoskeletal disorders symptoms, musculoskeletal disorder experience. For the survey, 118 expert players participated. The data from the survey were analyzed by correlation analysis and chi-square analysis. Results: The symptoms of musculoskeletal disorders and the severe pain from musculoskeletal disorders were observed at neck, shoulder, back and knee. The musculoskeletal experience was statistically related to the factor of body height in Gayageum and Geomungo. In addition, the musculoskeletal experience in Geomungo was related to age and career. However, the musculoskeletal experience in Ajaeng and Haegeum was only related to the factor of hobby. The musculoskeletal experience in Daegeum and Piri was related to stretching. In addition, there was a statistical significance between the musculoskeletal experience and sex in Daegum. In Samul instruments, the statistical significance was observed at age, BMI, career and stretching. Conclusion: The symptoms of playing-related musculoskeletal disorders of traditional Korean musical players were prevalently observed at neck, shoulder, back and knee. In addition, these symptoms were related to the various demographic factors such as age, body height, BMI, career, sex, hobby and stretching. Application: The results of this study can be used as the preliminary data for preventing the musculoskeletal injuries of traditional Korean musical instrument players.
\end{abstract}

Keywords: Traditional Korean instruments, Musculoskeletal disorders, String instrument, Wind instrument, Samul instrument

\section{Introduction}

1983년 Aspen에서는 악기 연주자들의 건강문제에 관 한 첫 회의(The conference on medical problems in performing artists as part of the Aspen Music Festival) 가 열렸고 그 이후 악기 연주자들의 건강문제를 다루는 연
구들이 활발하게 진행되고 있다(Hoppmann, 2001). 그리하 여 외국에서는 현재 악기 연주자들이 근골격계 질환에 노출 된 고 위험 직업 군으로 평가 받고 있다.

외국 기악 연주들에게서 주로 보고되는 건강문제로는 근 골격계 질환, 소음성 난청, 무대공포증 등이 있는데 그 중에 서도 근골격계 질환이 가장 빈번한 것으로 알려져 있다(Fry et al., 1989; Lockwood, 1989; Rom, 1998; Kahari et al.,

Corresponding Author: Seung Nam Min. Department of Industrial and Management Engineering, Hanyang University, Ansan, $426-791$.

Mobile: +82-10-4104-2914, E-mail: msnijn12@hanmail.net

Copyright@2012 by Ergonomics Society of Korea(pISSN:1229-1684 eISSN:2093-8462). All right reserved.

(c) This is an open-access article distributed under the terms of the Creative Commons Attribution Non-Commercial License(http://creativecommons.org/licenses/by-nc/3.0/), which permits unrestricted non-commercial use, distribution, and reproduction in any medium, provided the original work is properly cited. http://www.esk.or.kr 
2001; Brandfonbrener, 2004; Hagberg et al., 2005). 특 히 대부분의 근골격계 질환이 상지 부위에 집중되어 있다는 사실이 보고되고 있다(Fry, 1986, 1987; Hoppmann et al., 1989; Lockwood, 1989; Gunderson, 1997; Zara and Farewell, 1997; Zara, 1998; Hoppmann, 2001; Heidi, 2002). Anderson(1988), Lockwood(1989)은 연주자와 관련된 근골격계 질환에는 주로 목, 어깨, 팔 등의 상지에 나타나는 근 손상, 염좌, 건염, 점액낭염, 인대손상, 연골 및 골의 손상 등이 있다고 보고하였다. 그리고 초기에는 가벼운 통증, 저림, 얼얼함 등의 증상으로 시작하지만, 계속 진행되 면 운동마비, 근육위축 등으로 발전할 수 있다고 하였다. Robinson et al. (2002)는 일반적으로 연주자와 관련된 근 골격계 질환의 원인은 환경 요인(온도, 제한된 장소, 장비, 마루면, 빛), 물리적 요인(부적절한 자세, 무리한 힘, 반복, 부적절한 휴식, 접촉 스트레스, 진동), 개인적 요인(나이, 성 별, 신체적 적합성, 영양, 자세, 약물 복용 여부, 건강상태 등) 의 3 가지 항목으로 구성되어 있다고 하였다. Pratt et al. (1992), Larson et al. (1993), Roach et al.(1994), Zara and Farewell(1997)은 연주자와 관련된 증상 유병률은 성 인 기악 연주자의 경우 39 87\%로 하였다. 그리고 Fry et al.(1988), Lockwood(1988), Grieco et al.(1989)은 학 생 기악 연주자의 경우는 연주자와 관련된 증상 유병률이 34 62\%라고 보고하고 있다.

국내에서도 기악 연주자들의 건강문제에 관심을 가지고 다양한 연구들이 진행되고 있다. Sung et al. (2000)는 연주 자의 연주행위는 공통적으로 손 및 상지를 사용하여 건반을 짚는 동작이나 활을 켜는 동작과 같이 매우 정교하고 빠른 속도의 반복적인 동작을 필요로 하며 악기를 지지하기 위해 불안정하고 자연스럽지 못한 자세의 유지가 요구되며 이러 한 동작과 자세들을 연주행위 동안에 적절한 휴식이 없이 지속적으로 수행해야만 하는 특성을 갖는다고 하였다. 그리 고 Koh et al. (2006)는 대부분의 연주자들은 아주 어릴 적 부터 전공 악기를 다루어 왔기 때문에 오랜 기간의 연주경 력을 가지고 있다고 하였고, 악기의 종류에 따라 크기나 무 게가 다르고 연주동작과 악기를 지지하는 연주자세가 연주 자마다 다르다고 하였다. 그리고 악기를 지지하는 연주자세 가 연주자마다 다른 특성을 가진다고 하였다. 그러나 대부분 의 연구가 관현악 연주 대상이거나 현악기를 대상으로 하고 있을 뿐 전통 국악기 연주자들을 대상으로 한 연구가 전혀 없는 실정이다. 전통 국악기 연주자들 역시 악기 별 다양한 형태의 근골격계 증상을 보이고 있으며 통증을 호소하고 있 지만 이들에 대한 연구가 없는 상황으로 이에 대한 근골격계 질환 가능성 및 예방을 위한 기초 자료의 수집이 절실하다고 할 수 있다.

그리하여 본 연구의 목적은 국악기 연주자를 대상으로 한
근골격계 질환 실태 조사를 통해 국악기 연주자들의 근골격 계 질환 실태 기초 자료를 수집하는데 있다.

\section{Method}

본 연구의 전체적인 연구흐름은 Figure 1 과 같다. 연구는 크게 3 단계로 진행이 되며 각 단계는 포커스 그룹 인터뷰, 설문지 개발, 설문 조사로 구성이 되어 있다.

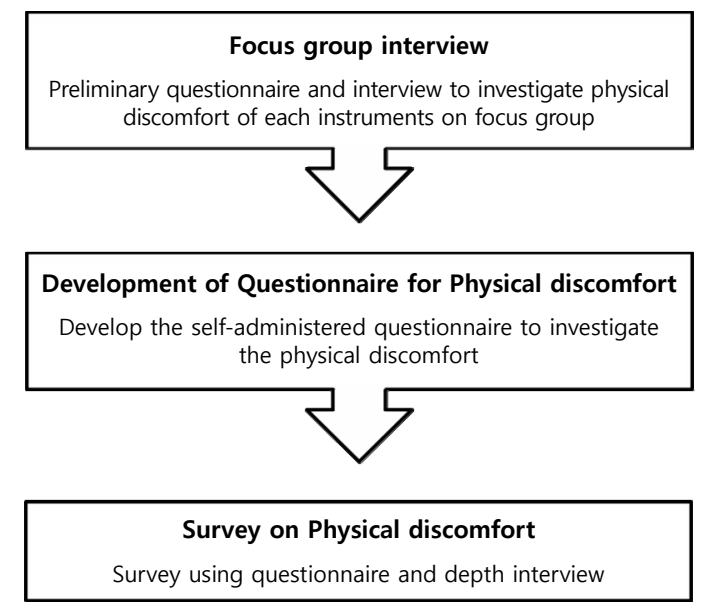

Figure 1. Overall research procedure

\subsection{Focus group interview}

국악기 연주자들 대상으로 한 근골격계 증상 조사 설문지 를 개발을 위하여 국악 전문가를 대상으로 한 포커스 그룹을 선정하였다. 포커스 그룹은 다양한 국악기 연주 경험이 있는 12 명의 국악 원로와 인간공학 전문가로 구성을 하였다. 포 커스 그룹 인터뷰로부터 수집된 다양한 의견과 한국산업안 전보건공단에서 제공하고 있는 유해요인조사 평가용 근골격 계 질환 증상 설문지의 일부를 발췌하여 새로운 형태의 근골 격계 증상 조사 설문지 초안을 개발하였다.

\subsection{Questionnaire development}

국악 연구원 전문가와 연주 단원의 의견을 반영하여 최종 적으로 국악 연주자용 근골격계 질환 증상 조사 설문지를 개발하였다. 설문지는 크게 연주자들의 개인 특성, 연주 특 성, 신체부담 부위 및 정도, 근골격계 질환 경험으로 구성이 되어 있다. 개인 특성은 연령, 성별, 키, 몸무게, 운동 여부, 
Table 1. Introduction to Korean traditional instruments

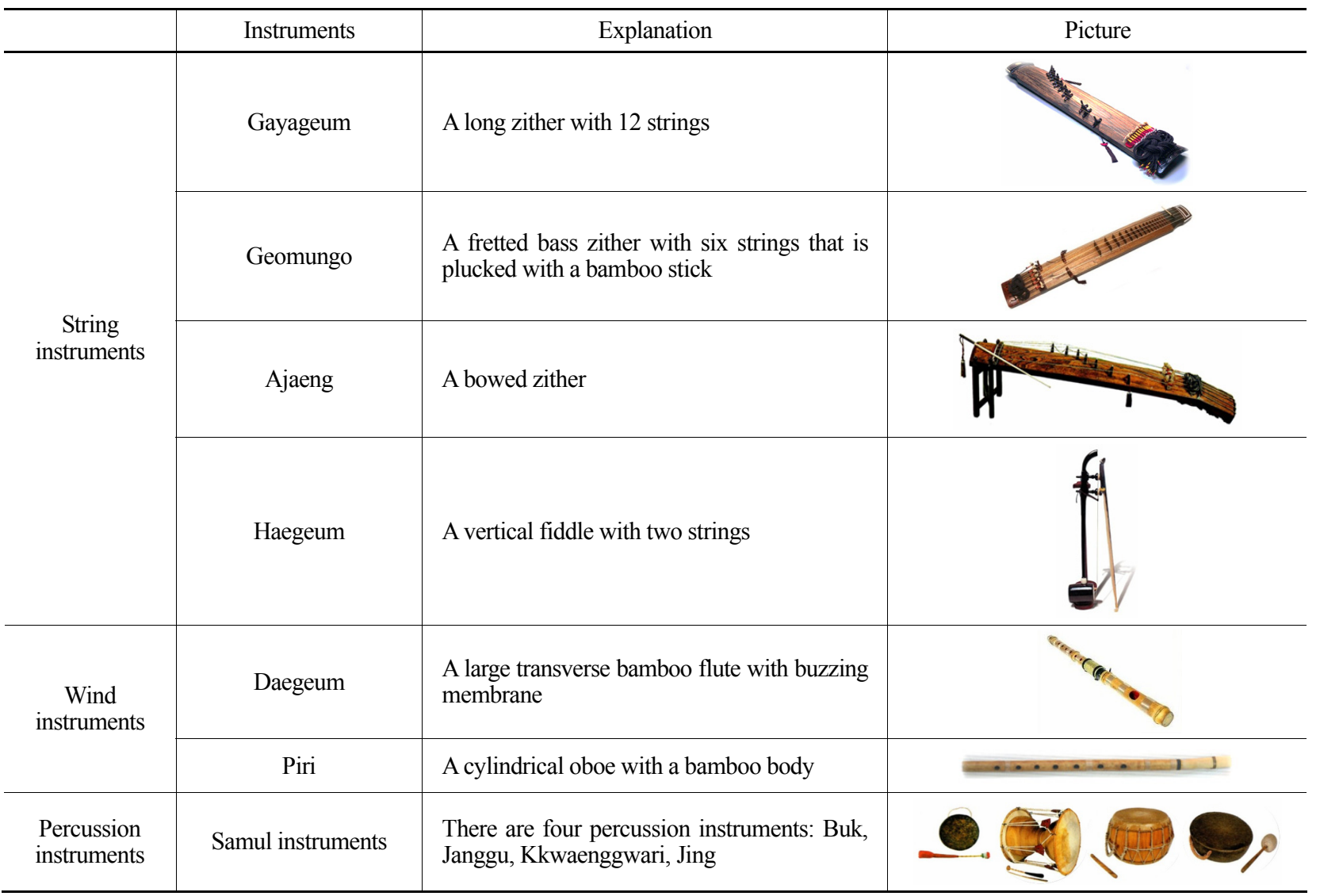

취미활동, 음주 여부, 흡연 여부가 조사되었고, 연주 특성에 서는 연주경력, 평상시 연주 정도, 공연 시 연주강도, 스트 레칭 여부가 조사되었다. 신체부담 부위 및 정도에서는 신체 부위 별 통증 부위, 통증 부위의 통증 정도, 통증 시 조치방 법이 조사되었다. 근골격계 질환 경험에서는 근골격계 질환 경험 유무와 치료방법 등에 대한 정보를 수집하였다.

\subsection{Musculoskeletal symptoms survey}

본 설문 조사는 서울, 부산, 남원, 진도 국악원에서 수련하 고 있는 연주 단원을 대상으로 하였으며 188 명이 설문에 참 여하였다. 국악기 별 연주자들은 가야금 28 명, 거문고 20 명, 대금 33명, 사물 37명, 아쟁 11 명, 피리 32명, 해금 27 명, 타악 7 명으로 구성되었다. 설문지 조사에 사용된 국악기의 종류는 Table 1 과 같다.

\section{Results}

\subsection{Demographic characteristics}

설문 응답자 188 명 중 남자가 $52 \%$, 여자가 $48 \%$ 이었고, 평균 나이는 34.5 세였다. 키의 평균은 $167.8 \mathrm{~cm}$, 몸무게의 평균은 $64.2 \mathrm{~kg}$, 비만도(BMI) 의 평균은 $24.9 \mathrm{~kg} / \mathrm{m}^{2}$ 으로 조 사되었다. 전체 설문 응답자의 $56 \%$ 가 평소에 운동을 하고 있었고, 운동의 강도는 낮음 $(26 \%)$, 중간 $(66 \%)$, 높음 $(8 \%)$ 으로 나타났으며, 중간과 낮은 수준이 전체의 $92 \%$ 를 차지 하고 있었다. 전체의 $34 \%$ 가 취미활동을 하고 있었고 취미 활동의 주 형태는 독서, 영화감상이 높게 조사되었다. 음주 와 흡연 여부와 관련해서는 전체의 $60 \%, 23 \%$ 가 각각 음주 와 흡연을 하고 있었다. 악기 연주 전 스트레칭 또는 준비운 동을 하는 경우가 전체의 $44 \%$ 로 낮게 나타났다(Table 2).

\subsection{Playing experience}

국악기 별 악기 연주경력을 조사하였다. 평균 연주경력은 
20.56년 $( \pm 2.13)$ 으로 나타났다. 각 국악기 별로 보면, 가야 금 23.5년, 사물 악기 22.7년, 거문고 21.7년, 대금과 피리 19.7년, 해금 19.2년, 아쟁 17.5년 순으로 나타났다. 공연 시와 평상 시 연주시간을 비교해 보았다. 그 결과 가야금, 거 문고, 대금, 해금 악기 모두 평상 시 연습시간보다 공연 시 연습시간이 훨씬 높은 것으로 나타났다 $(p<0.01)$. 그러나 다 른 악기의 경우 평상 시 연주시간과 공연 시 연주시간 사이 에 통계적 유의성이 발견되지 않았다(Table 3). 이러한 결 과는 국악인들이 1 년에 약 100 회 정도 되는 공연을 실시하 는 것을 감안한다면, 공연 시 연주가 근골격계 질환에 원인

Table 2. Demographic characteristics

\begin{tabular}{l|l|c}
\hline \multicolumn{2}{c|}{ Variable } & Statistic \\
\hline Gender & Male & $98(52 \%)$ \\
& Female & $90(48 \%)$ \\
\hline Age & & $34.5 \pm 9.0$ \\
\hline Physical index & & \\
& Height $(\mathrm{cm})$ & $167.8 \pm 8.0$ \\
& Weight $(\mathrm{kg})$ & $64.2 \pm 14.19$ \\
& BMI $\left(\mathrm{kg} / \mathrm{m}^{2}\right)$ & $24.9 \pm 11.18$ \\
\hline Exercise & & $101(56 \%)$ \\
& Strength & $8(8 \%)$ \\
& High level & $77(66 \%)$ \\
\hline Hobby & Moderate level & $26(26 \%)$ \\
\hline Drinking & Low level & $64(34 \%)$ \\
\hline Smoking & & $115(60 \%)$ \\
\hline Stretching & & $40(23 \%)$ \\
\hline
\end{tabular}

Table 3. Experience for playing instruments

\begin{tabular}{l|c|c|c}
\hline Instrument & $\begin{array}{c}\text { Career } \\
\text { (year) }\end{array}$ & $\begin{array}{c}\text { Practice period } \\
\text { before } \\
\text { performance } \\
\text { (min) }\end{array}$ & $\begin{array}{c}\text { Practice period } \\
\text { in daily life } \\
\text { (min) }\end{array}$ \\
\hline Gayageum & 23.5 & 320.0 & 165.0 \\
\hline Geomungo & 21.7 & 240.0 & 170.5 \\
\hline Ajaeng & 17.5 & 240.0 & 177.0 \\
\hline Haegeum & 19.2 & 314.3 & 190.8 \\
\hline Daegeum & 19.7 & 214.4 & 154.7 \\
\hline Piri & 19.7 & 213.2 & 183.2 \\
\hline Samul instruments & 22.7 & 67.5 & 150.0 \\
\hline
\end{tabular}

이 될 수 있을 거라 판단된다.

\subsection{Prevalence of musculoskeletal symptoms}

연주형태에 따라 통증을 호소하는 부위가 서로 다르게 나타났다. 현악기의 경우, 가야금에서는 목 $(78.6 \%)$, 허리 $(75 \%)$, 어깨와 무릎 $(71.4 \%)$ 순으로 나타났고, 거문고에서 는 어깨 $(95 \%)$, 목 $(80 \%)$, 무릎과 손목 $(65 \%)$, 손가락과 허 리 $(60 \%)$, 아래팔 $(55 \%)$ 순으로 나타났다.

아쟁에서는 목(100\%), 어깨(90.9\%), 허리(72.7\%), 무 릎, 손목, 아래팔, 윗팔 $(54.5 \%)$ 순으로 나타났고, 해금에서 는 어깨 $(84.8 \%)$, 손가락 $(74.1 \%)$, 목 $(70.4 \%)$, 허리와 무 릎 $(63 \%)$ 순으로 나타났다. 관악기의 경우, 대금에서는 목 $(87.9 \%)$, 어깨 $(84.8 \%)$, 무릎 $(69.7 \%)$, 허리 $(60.6 \%)$, 손목 (51.5\%) 순으로 나타났고, 피리에서는 어깨와 목 $(59.4 \%)$, 무릎 $(53.1 \%)$ 순으로 나타났다. 타 악기의 경우 사물 악기에 서는 어깨(76.7\%), 목(70.0\%), 허리 $(60.0 \%)$ 순으로 나타 났다(Table 4). 모든 악기에서 무릎, 목, 어깨, 허리의 증상 호소가 높았다는 것을 확인할 수 있었다. 통증을 호소한 연 주자들을 대상으로 한 통증의 정도를 평가한 설문에서는 5점 만점 중 4점 이상(심한 통증)을 호소한 부위가, 현악기 의 경우 거문고에서는 허리(4.0), 아쟁에서는 허리(4.3), 어 깨 (4.2) 순으로 나타났다. 관악기의 경우, 해금에서는 손가 락(4.5), 허리, 어깨, 목(4.0) 순으로 나타났고, 대금에서는 어깨, 허리 (4.2), 목(4.1) 순으로 나타났다. 반면에 사물놀이 의 경우 타 악기의 비해 통증의 호소가 상대적으로 낮게 나 타났다(Table 5).

\subsection{The analysis of relationship between demographic variables and factors and prevalence of symptoms}

인구통계학적 변수와 근골격계 증상 호소와의 연관성을 통계적으로 분석하기 위하여 명목형 데이터는 카이제곱 분 석, 수치형 데이터는 상관분석을 실시하였다.

현악기의 경우, 같은 현악기라도 악기에 따라 근골격계 질 환 증상과 연관성이 높은 요인들이 서로 다르게 나타났다. 가야금과 거문고는 모두 키에서 통계적 유의성 $(p<0.1)$ 이 나타났다. 즉 키가 클수록 근골격계 질환 증상과의 연관성이 높게 나타나는 경향이 있었다. 추가로 거문고는 연령과 경력 에서도 상관관계가 나타났는데 연령이 증가하거나 경력이 증가할 수록 증상이 덜 나타나는 것으로 나타났다. 아쟁과 해금은 취미생활 여부와 연관성이 있는 것으로 나타났는데 취미생활의 내용으로는 운동과 관련된 취미로 헬스, 요가, 자전거, 수영 등이 있었다.

관악기는 대금과 피리를 대상으로 조사되었다. 대금에서는 
Table 4. Prevalence of musculoskeletal symptoms in body parts

\begin{tabular}{l|r|c|c|c|c|c|c|c|c|c|c|c|c|c}
\hline Instruments & Neck & Shoulder & $\begin{array}{c}\text { Upper } \\
\text { arm }\end{array}$ & Elbow & Forearm & Wrist & Palm & Finger & Back & Hip & Thigh & Knee & Calf & $\begin{array}{c}\text { Ankle } \\
\text { /foot }\end{array}$ \\
\hline Gayageum & 78.6 & 71.4 & 35.7 & 25.0 & 35.7 & 42.9 & 25.0 & 39.3 & 75.0 & 46.4 & 28.6 & 71.4 & 32.1 & 35.7 \\
\hline Geomungo & 80.0 & 95.0 & 35.0 & 10.0 & 55.0 & 65.0 & 25.0 & 60.0 & 60.0 & 40.0 & 25.0 & 65.0 & 20.0 & 45.0 \\
\hline Ajaeng & 100.0 & 90.9 & 54.5 & 27.3 & 54.5 & 54.5 & 0.0 & 45.5 & 72.7 & 27.3 & 9.1 & 54.5 & 9.1 & 9.1 \\
\hline Haegeum & 70.4 & 81.5 & 25.9 & 22.2 & 29.6 & 48.1 & 18.5 & 74.1 & 63.0 & 48.1 & 25.9 & 63.0 & 40.7 & 44.4 \\
\hline Daegeum & 87.9 & 84.8 & 48.5 & 24.2 & 33.3 & 51.5 & 24.2 & 39.4 & 60.6 & 39.4 & 33.3 & 69.7 & 30.3 & 36.4 \\
\hline Piri & 59.4 & 59.4 & 21.9 & 18.8 & 12.5 & 31.3 & 9.4 & 18.8 & 46.9 & 15.6 & 12.5 & 53.1 & 18.8 & 34.4 \\
\hline Samul instruments & 70.0 & 76.7 & 26.7 & 16.7 & 30.0 & 36.7 & 10.0 & 33.3 & 60.0 & 23.3 & 3.3 & 50.0 & 30.0 & 50.0 \\
\hline
\end{tabular}

Table 5. Degree of musculoskeletal symptoms in body parts

\begin{tabular}{l|c|c|c|c|c|c|c|c|c|c|c|c|c|c}
\hline Instruments & Neck & Shoulder & $\begin{array}{c}\text { Upper } \\
\text { arm }\end{array}$ & Elbow & Forearm & Wrist & Palm & Finger & Back & Hip & Thigh & Knee & Calf & $\begin{array}{c}\text { Ankle } \\
\text { /foot }\end{array}$ \\
\hline Gayageum & 3.4 & 3.7 & 2.0 & 2.6 & 2.3 & 3.3 & 1.6 & 2.9 & 3.9 & 3.4 & 3.6 & 2.8 & 2.6 & 2.5 \\
\hline Geomungo & 3.8 & 3.8 & 1.9 & 2.0 & 1.8 & 2.7 & 1.2 & 3.1 & $\mathbf{4 . 0}$ & 2.6 & 2.6 & 3.3 & 2.5 & 1.8 \\
\hline Ajaeng & 3.5 & $\mathbf{4 . 2}$ & 3.2 & 2.0 & 2.2 & 3.0 & 0.0 & 3.0 & $\mathbf{4 . 3}$ & 4.3 & 2.0 & 3.0 & 1.0 & 3.0 \\
\hline Haegeum & $\mathbf{4 . 0}$ & $\mathbf{4 . 0}$ & 3.0 & 2.3 & 3.0 & 3.4 & 2.0 & $\mathbf{4 . 5}$ & $\mathbf{4 . 0}$ & 3.6 & 2.0 & 3.0 & 2.5 & 3.4 \\
\hline Daegeum & $\mathbf{4 . 1}$ & $\mathbf{4 . 2}$ & 3.3 & 1.4 & 3.2 & 3.5 & 1.9 & 3.1 & $\mathbf{4 . 2}$ & 3.1 & 1.8 & 3.0 & 2.0 & 2.3 \\
\hline Piri & 3.7 & 3.8 & 1.9 & 1.8 & 1.5 & 2.4 & 2.3 & 1.5 & 3.9 & 3.2 & 3.0 & 2.9 & 2.7 & 2.0 \\
\hline Samul instruments & 3.4 & 3.7 & 2.6 & 3.6 & 2.8 & 2.5 & 3.3 & 2.3 & 3.3 & 2.0 & 5.0 & 3.2 & 2.9 & 3.5 \\
\hline
\end{tabular}

Boldfaced numbers indicate the score of equal to 4 point and above.

Table 6. Correlation analysis between musculoskeletal experience and demographic variables

\begin{tabular}{|c|c|c|c|c|c|c|c|c|c|c|}
\hline \multirow{2}{*}{ Instruments } & \multicolumn{2}{|c|}{ Age } & \multicolumn{2}{|c|}{ Stature } & \multicolumn{2}{|c|}{ Weight } & \multicolumn{2}{|c|}{ BMI } & \multicolumn{2}{|c|}{ Career } \\
\hline & $r$ & $p$-value & $r$ & $p$-value & $r$ & $p$-value & $r$ & $p$-value & $r$ & $p$-value \\
\hline Gayageum & 0.10 & 0.629 & 0.18 & $0.054^{*}$ & 0.03 & 0.903 & -0.21 & 0.307 & 0.09 & 0.661 \\
\hline Geomungo & -0.46 & $0.050^{*}$ & 0.43 & $0.062^{*}$ & 0.15 & 0.571 & 0.13 & 0.628 & -0.47 & $0.038^{*}$ \\
\hline Ajaeng & 0.41 & 0.208 & 0.23 & 0.531 & 0.30 & 0.398 & 0.22 & 0.601 & 0.50 & 0.115 \\
\hline Haegeum & 0.08 & 0.693 & -0.09 & 0.657 & -0.16 & 0.425 & -0.18 & 0.374 & -0.20 & 0.325 \\
\hline Daegeum & 0.09 & 0.616 & 0.24 & 0.177 & 0.22 & 0.226 & 0.23 & 0.201 & 0.02 & 0.932 \\
\hline Piri & 0.17 & 0.348 & 0.17 & 0.360 & -0.06 & 0.738 & -0.11 & 0.562 & 0.05 & 0.793 \\
\hline Samul instruments & -0.45 & $0.014^{*}$ & 0.05 & 0.795 & 0.32 & 0.100 & 0.35 & $0.069^{*}$ & -0.39 & $0.038^{*}$ \\
\hline
\end{tabular}

$r$ : coefficient of correlation

$*: p<0.1$

성별과 연주 전 스트레칭 여부가 유의하게 나타났다. 세부적 으로 보면 성별의 경우 남성 (89\%)이 여성 $(54 \%)$ 보다 근골 격계 질환을 경험의 비율이 높았고, 스트레칭의 경우, 스트 레칭을 한 경우 $(24 \%)$ 가 안 한 경우 $(53 \%)$ 보다 근골격계 질환 경험의 비율이 낮았다. 피리는 스트레칭 여부에서만 연 관성이 나타났다. 스트레칭을 한 경우 $(32 \%)$ 가 스트레칭을 안 한 경우 $(62 \%)$ 보다 근골격계 질환 경험이 낮게 나타났다.
사물악기는 다양한 연령, BMI, 경력, 스트레칭 여부의 요 인에서 연관성이 발견되었다. 연령과 $\mathrm{BMI}$ 에서 통계적 유의 성 $(p<0.1)$ 이 나타났다. 즉, 연령이 증가할수록 근골격계 질 환 증상과의 연관성이 낮게 나타나는 경향이 있었고, $\mathrm{BMI}$ 가 높을수록 근골격계 질환 증상과의 연관성이 높게 나타났다 (Table 6, 7). 
Table 7. Chi-square analysis between musculoskeletal experience and demographic variables

\begin{tabular}{|c|c|c|c|c|c|c|c|c|c|c|c|c|}
\hline \multirow{2}{*}{ Instruments } & \multicolumn{2}{|c|}{ Gender } & \multicolumn{2}{|c|}{ Exercise } & \multicolumn{2}{|c|}{ Hobby } & \multicolumn{2}{|c|}{ Smoking } & \multicolumn{2}{|c|}{ Drinking } & \multicolumn{2}{|c|}{ Stretching } \\
\hline & $\chi^{2}$ & $p$-value & $\chi^{2}$ & $p$-value & $\chi^{2}$ & $p$-value & $\chi^{2}$ & $p$-value & $\chi^{2}$ & $p$-value & $\chi^{2}$ & $p$-value \\
\hline Gayageum & 0.24 & 0.611 & 0.18 & 0.611 & 1.34 & 0.212 & 3.64 & 0.359 & 0.56 & 0.562 & 0.00 & 0.946 \\
\hline Geomungo & 0.27 & 0.628 & 0.95 & 0.355 & 1.82 & 0.196 & 0.03 & 0.876 & 1.83 & 0.196 & 0.27 & 0.628 \\
\hline Haegeum & 0.59 & 0.463 & 0.30 & 0.603 & 6.75 & $0.008^{*}$ & 0.55 & 0.478 & 0.31 & 0.597 & 1.92 & 0.179 \\
\hline Ajaeng & 0.08 & 0.808 & 0.02 & 0.910 & 3.23 & $0.085^{*}$ & 0.41 & 0.568 & 0.92 & 0.389 & 2.93 & 0.104 \\
\hline Piri & 0.55 & 0.474 & 0.25 & 0.631 & 0.00 & 0.962 & 0.71 & 0.416 & 0.37 & 0.557 & 2.82 & $0.099^{*}$ \\
\hline Daegeum & 3.41 & $0.068^{*}$ & 0.08 & 0.792 & 0.23 & 0.642 & 0.00 & 1.000 & 0.11 & 0.751 & 3.02 & $0.087^{*}$ \\
\hline Samul instruments & 0.01 & 0.931 & 1.17 & 0.297 & 1.21 & 0.288 & 0.00 & 0.979 & 0.03 & 0.877 & 4.19 & $0.042^{*}$ \\
\hline
\end{tabular}

$*: p<0.1$

\section{Discussion}

본 연구는 국악기 연주자의 개인 특성과 연주 경험, 근골 격계 증상 발현 부위, 근골격계 질환 경험 유무를 조사하여, 국악기 연주자들의 근골격계 질환 현황 자료를 수집하고, 향 후 이를 예방하기 위한 기초 자료를 마련하는데 그 의의가 있다.

국악기 연주자들이 근골격계 증상을 호소하는 부위는 서 양 악기 연주자들이 호소하는 부위와 일부 공통점이 발견 되었지만 서양 악기 연주자들에 비해 다양한 부위에서 근 골격계 증상을 호소하고 있었다. 서양 연주는 상지를 주로 사용하는 연주 특성에 따라 상지 쪽 부위에서 근골격계 증상을 호소하는 경우가 많았지만(Dawson, 1988, 1995; Knishkowy and Lederman, 1986), 국악기 연주자는 모든 악기에서 무릎, 목, 어깨, 허리의 증상 호소가 관찰되었다. 이러한 차이는 주로 연주형태가 영향을 미치는 것으로 판단 할 수 있다. 서양의 약기들은 대체적으로 서서 연주를 하거 나 의자에 앉아 연주를 하는 경우가 많은 반면 국악기의 경 우는 바닥에 앉아 비대칭 가부좌 자세로 연주를 하는 경우 가 많기 때문에 서양 악기 연주자들에 비해 허리를 비롯한 하지 부위에도 근골격계 증상에 대한 호소가 높게 나타난 것 으로 판단된다. 특히 현악기의 경우 아래팔, 손목, 손가락, 목, 어깨, 허리, 무릎 등 신체의 많은 부위에서 근골격계 증 상이 발견되고 있고 통증 정도도 심하게 관찰되고 있어 조속 한 관리가 필요할 것으로 생각된다.

본 연구의 결과 중 거문고와 사물 악기의 경우 연령이 증 가하고, 경력이 증가할수록 근골격계 증상에 대한 경험이 낮 게 나타나는 현상을 관찰하였다. 일반적으로 연령이 증가하 면 경력이 같이 늘어나고 근골격계 증상에 더욱 쉽게 노출될 것으로 생각할 수 있는데 이러한 개념과는 반대의 결과가 나타났다. 이는 다른 연구에서도 비슷하게 관찰할 수 있다.
Virokannas et al.(1999)은 55세 작업자의 작업경력과 근 골격계 질환에 대한 상관관계를 분석했는데 작업경력(work career)은 근골격계 증상과 관련성이 있었고 특히 높은 작 업경력(advanced work career)을 지닌 사람들에게서 근 골격계 증상이 낮게 나타났다고 하였다. 또한 Salik and Özcan(2004)은 물리치료사에 대한 작업경력과 근골격계 질환에 대한 상관성을 보았다. 그 결과 작업경력이 낮은 물 리치료사에게서 근골격계 증상이 높게 나타났는데, 이는 물 리치료 시술에 대한 기술 및 지식부족으로 인한 것이라고 하였다. 본 연구에서 또한 이러한 맥락의 결과가 발견되었고 이는 경력에 따른 연주기술과 밀접한 연관성이 있을 것이라 판단된다.

거문고와 가야금의 경우 키가 증가할수록 근골격계 증상 에 대한 경험이 높아지는 현상을 관찰하였다. 반면 비슷한 형태의 아쟁에서는 신장과 근골격계 증상에 대한 경험의 상 관성이 발견되지 않았다. 이는 현악기의 연주자세 때문으로 생각된다. 가야금과 거문고는 연주 시 비대칭 가부좌 자세를 주로 취하고 왼쪽 손목을 굽혀 현을 눌러 장력을 조절하고 오른쪽 손목을 굽혀 손가락으로 현을 반복적으로 뜯는 연주 자세를 보여준다. 반면에 아쟁은 왼쪽 손목은 가야금, 거문 고와 비슷한 자세를 취하지만 오른쪽 손은 활을 사용하여 연주를 하는 자세를 보여준다. 그리하여 키의 요소는 가야금, 거문고에서만 영향을 주는 것으로 판단된다.

일반적으로 스트레칭은 근골격계 질환을 예방하기 위한 예방 프로그램으로 많이 활용되고 있다. 국악기 연주자들도 악기 연주 전 스트레칭을 통해 근골격계 질환을 예방하는 데 도움을 받을 수 있을 것으로 생각된다. 본 연구에서도 피리, 대금, 사물 악기 연주자들의 경우 스트레칭이 근골격계 증상 에 대한 경험을 줄여주고 있다는 결과를 확인할 수 있었다. Hansen and Reed(2006), Costa et al.(2008)의 연구에 의하면 스트레칭은 근골격계 질환을 예방할 수 있는 효과를 가져올 수 있다는 연구와 같이 연주 전에 스트레칭 및 준비 
운동은 예방 프로그램으로서의 좋은 수단으로 활용이 가능 할 것으로 생각된다.

본 연구를 통해 국악기 연주자들은 서양의 다른 악기 연주 자들과는 다르게 신체 전체 부위에서 다양한 형태의 근골격 계 증상을 호소하고 있는 것을 알 수 있었고 그 통증의 정도 도 매우 심하다는 것을 확인할 수 있었다. 국악기 연주자의 경우도 일반 작업자처럼 근골격계 질환이 발생하면 비용적 인 손실이나 인적 손실이 발생하게 되기 때문에 연주자가 그러한 단계로 접어들기 전에 일상 업무 빨리 복귀하게 하 기 위하여 work hardening 프로그램 도입을 고려해볼 수 있을 것으로 생각된다. Work hardening은 고객의 생산성을 증가시키는 결과를 가져올 수 있는 작업 중심의 치료 프로그 램을 의미한다. 국악이 연주자들의 경우는 국악기 연주를 하 기 위해 사용되는 근육군을 찾아내고 해당 근육에 대한 스트 레칭과 단련을 통해 근골격계 질환을 예방할 수 있는 프로그 램으로 고려해 볼 수 있다. 이러한 work hardening 프로그 램을 통해 증상 호소 부위에 대한 트레이닝을 한다면 좀더 효과적인 근골격계 예방 프로그램으로서의 좋은 수단으로 활용도 가능할 것으로 판단된다(Schonstein et al., 2002).

\section{Conclusion}

본 연구는 국악기 연주자의 근골격계 증상 부위와 그 원인 을 규명하기 위한 정량적 역학 조사로써 그 의미가 크다고 하겠다.

현재 규명되어 있는 통증 유발요인에 대해서는 국악기의 특징과 연주자의 특징을 세심히 고려하여 그 예방과 치료방 법이 제안되어야 할 것이고, 특정 단일 원인을 규명하지 못 한 통증의 경우에는 근골격계 질환 예방에 필요한 운동 및 스트레칭 프로그램 등을 개발하여 이를 연습과정과 연주과 정에 적용하는 것이 필요하다. 이제까지 개인 별로 관리해 오던 국악기 연주자들의 통증 문제를 해결하고 국악기 연주 자들의 연주활동을 돕고 연주력을 향상시키기 위해서는 과 학적이고 다면적인 예방 프로그램의 체계적 수립이 필요한 시점이 되었다고 판단된다. 이를 위해서 본 연구에서 입증된 통계적 결과가 적극적으로 활용되어야 할 것이고, 추후 본 연구 결과를 기초로 정밀 분석을 위한 인체공학적 조사와 근 골격계 질환 예방을 위한 악기 별 맞춤형 근육 강화 및 스트 레칭 프로그램 개발이 진행되어야 할 것이다. 본 연구의 공 학적인 결과가 국악기 연주자들의 건강을 증진시키고 이를 통한 한국전통국악기 연주의 수준을 향상시킬 수 있을 것으 로 기대된다. 끝으로 본 연구의 결과는 그 활용 여부에 따라 공학적 연구 결과가 문화적 보전성을 증대시키는 매우 흥미
로운 사례로 인식될 것이다.

\section{References}

Anderson, V. P., Cumulative trauma disorders: A manual for musculoskeletal disease of the upper limbs, National Institute for Occupational Safety and Health (NIOSH). 1988.

Brandfonbrener, A. G., Musculoskeletal problems of instrumental musicians, Hand clinics, 19(2), 231-239, 2004.

Costa, B. R. and Vieira, E. R., Stretching to Reduce Work-Related Musculoskeletal Disorders: A Systematic Review, Journal of Rehabilitation Medicine, 40(5), 321-328, 2008.

Dawson, H. J., Hand and upper extremity problems in musicians; epidemiology and diagnosis, Medical Problem of Performing Artists, 3(1), 19, 1988.

Dawson, W. J., Experience with hand and upper extremity problems in 1,000 instrumentalists, Medical Problem of Performing Artists, 10(4), 128,1995 .

Fry, H. J. and Rowley, G. L., Music related upper limb pain in schoolchildren, Annals of the rheumatic diseases, 48(12), 998-1002, 1989.

Fry, H. J. H., Overuse syndrome in musicians: prevention and management, Lancet, 27(2), 728-731, 1986.

Fry, H. J. H., Prevalence of overuse(injury) syndrome in Australian music schools, British journal of industrial medicine, 44(1), 35-40, 1987.

Fry, H. J. H., The treatment of overuse syndrome in musicians. Results in 175 patients, Journal of the Royal Society of Medicine, 81(10), 572 $-575,1988$.

Grieco, A., Occhipinti, E., Colombini, D., Menoni, O., Bulgheroni, M., Frigo, C. and Boccardi, S., Muscular effort and musculo-skeletal disorders in piano students: electromyographic, clinical and preventive aspects, Ergonomics, 3(2), 697-716, 1989.

Gunderson, E., Moline, J. and Catalano, P., Risks of developing noiseinduced hearing loss in employees of urban music clubs, American journal of industrial medicine, 31(1), 75-79, 1997.

Hagberg, M., Thiringer, G. and Brandstrom, L., Incidence of tinnitus, impaired hearing and musculoskeletal disorders among students enroled in academic music education-a retrospective cohort study, International archives of occupational and environmental health, 78(7), 575-583, 2005.

Hansen, P. A. and Reed, K., Common Musculoskeletal Problems in the Performing Artist, Physical medicine and rehabilitation clinics of North America, 17(4), 789-801, 2006

Heidi, C., Five common causes of physical injury for violists: comments of a master teacher on approach to the instrument, Medical Problem of Performing Artists, 17(3), 128-130, 2002.

Hoppmann, R. A. and Patrone, N. A., A review of musculoskeletal problems in instrumental musicians, Semin Arthritis Rheum, 19(2), 117-126, 1989.

Hoppmann, R. A., Instrumental musicians' hazards, Occupational medicine, 
16(4), 619-631, 2001.

Kahari, K. R., Axelsson, A., Hellstrom, P. A. and Zachau, G., Hearing development in classical orchestral musicians. A follow-up study, Scandinavian audiology, 30(3), 141-149, 2001.

Knishkowy, B. and Lederman, R. J., Instrumental musicians with upper extremity disorders: a follow up study, Medical Problems of Performing Artists, (3), 85, 1986.

Koh, J. W., Lee, S. J., Kim, Y. K., Kim, I., Kwon, S. C., Park, S. B., Kim, M. J., Kim, S. W., Park, K. G., Kim, H. M., Song, J. W. and Song, J. C., The Prevalence of Playing-Related Musculoskeletal Disorders of Music College Freshmen Playing String Instruments, Korean Journal of Occupational Environment Medical, 18(3), 189-198, 2006.

Larsson, L. G., Baum, J., Mudholkar, G. S. and Kollia, G. D., Nature and impact of musculoskeletal problems in a population of musicians, Medical Problems of Performing Artists, 8(3), 73, 1993.

Lockwood, A. H., Medical problems in secondary school-aged musicians, Medical Problems of Performing Artists, 3(4), 129-132, 1988.

Lockwood, A. H., Medical problems of musicians. The New England Journal of Medicine, 320(4), 221-227, 1989.

Pratt, R. R., Jessop, S. G. and Niemann, B. K., Performance-related disorders among music majors at Brigham Young University, International Journal of Artist Medicine, 1, 7-20, 1992.

Roach, K. E., Martinez, M. A. and Anderson, N., Musculoskeletal pain in student instrumentalists: a comparison with the general student population, Medical Problems of Performing Artists, 9(4), 125-130, $1994 .$.

Robinson, D. and Zander, J., Preventing Musculoskeletal Injury (MSI) for Musicians and Dancers: A Resource Guide. Safety and Health in Arts production and Entertainment, 2002, (SHAP). http://www.shape.bc.ca/ resources/pdf/msi.pdf, (retrieved Feb 27, 2012)

Rom, W. N., Environmental and occupational medicine. 3rd ed, Philadelphia, New York, Lippincott Raven, 937-969, 1998.

Salik, Y. and Özcan, A., Work-related musculoskeletal disorders: A survey of physical therapists in Izmir-Turkey, BMC Musculoskeletal Disorders, 18, 5-27, 2004

Schonstein, E., Kenny, D. T., Keating, J. L. and Koes, B. W., Work conditioning, work hardening and functional restoration for workers with back and neck pain, The Cochrane database of systematic reviews, (1), CD001822, 2003.

Sung, N. J., Sakong, J. and Chung, J. H., Musculoskeletal disorders and related factors of symphony orchestra players, Korea Jouranl of Occupational Environment Medicine, 12(1), 48-58, 2000.

Virokannas, H., Rahkonen, M., Luoma, I., Rajala, U. and Uusimäki, A., Long-Term Musculoskeletal Disorders and Work Career in 55-YearOld Workers, Experimental Aging Research, 25(4), 301-306, 1999.

Zara, C. and Farewell, V. T., Musicians'playing-related musculoskeletal disorders: an examination of risk factors, American Journal of Industrial Medicine, 32(3), 292-300, 1997.
Zara, C., Playing-related musculoskeletal disorders in musicians: a systematic review of incidence and prevalence, Canadian medical association journal, 158(5), 1019-1025, 1998.

\section{Author listings}

Jung Yong Kim: jungkim@hanyang.ac.kr

Highest degree: $\mathrm{PhD}$, Department of Industrial Engineering, The Ohio state University

Position title: Professor, Department of Industrial and Management Engineering, Hanyang University

Areas of interest: Biomechancis, Biosignal analysis, Cognitive Psychology

Seung Nam Min: msnijn12@hanmail.net

Highest degree: $\mathrm{PhD}$, Department of Industrial Engineering, Hanyang University

Position title: Post Doc., Department of Industrial and Management Engineering, Hanyang University

Areas of interest: Biomechancis, Biosignal analysis, Cognitive Psychology, Safety Management, Physical User Interface

Young Jin Cho: soulian@hanyang.ac.kr

Highest degree: $\mathrm{PhD}$, Department of Industrial Engineering, Hanyang University

Position title: Researcher, Department of Industrial and Management Engineering, Hanyang University

Areas of interest: Biomechanics, Biosignal analysis, Safety Management, Physical User Interface

Jun Hyeok Choi: choijjun@gmail.com

Highest degree: BS, Department of Industrial and Management Industry, Hanyang University

Position title: Master's course, Department of Industrial and Management Engineering, Hanyang University

Areas of interest: Physical UI/UX, Service design, Cognitive Psychology, Neuroscience

Date Received : 2012-02-28

Date Revised : 2012-11-30

Date Accepted : 2012-12-03 